\title{
Quem conta um conto... reconhecendo as potencialidades da contação de histórias para o ensino de ciências
}

\author{
Danielle Sales* \\ Maylta Brandão dos Anjos** \\ Giselle Rôças***
}

\begin{abstract}
Resumo
A contação de histórias é um recurso didático lúdico, possibilitando que o ensino de ciências aconteça em suas várias dimensões. Assim, mais que uma breve história, as contações nos apontam caminhos, abrem um mundo de significados, fortalecendo nossos vínculos humanos, artísticos, sociais, educativos, culturais e afetivos. O objetivo da investigação foi compreender como a contação de histórias, enquanto recurso didático, contribui para as ações e práticas interdisciplinares no ensino de ciências. A análise dos resultados foi inspirada no método de análise das entrevistas narrativas apresentada por Muylaert et al. (2014), que entendem a narrativa como forma artesanal de comunicação, que transmite a experiência do entrevistado com determinada temática. A pesquisa realizada apresentou a abordagem interdisciplinar como amálgama para o ensino de ciências, utilizando as histórias como aporte de compreensão. Como resultado, observou-se a importância de se trabalhar com o ensino de ciências atrelado às demais disciplinas, de forma a dar significado aos elementos que são apresentados aos alunos. Desta forma, o pensar interdisciplinar transcende as paredes da escola, trazendo conteúdos de vivência do próprio aluno para a sala de aula.

Palavras-chave: contação de histórias, ensino de ciências, interdisciplinaridade.
\end{abstract}

\section{Once upon a tale... Story telling possibilities as a source to Science Education}

Abstract

Storytelling is a fun teaching resource that enables Science Education to take place in its multiple dimensions. Thus, more than a brief story, the storytelling brings paths, presenting a world of meanings and strengthening our human, artistic, social, educational, cultural and affective bounds. The purpose of this research is to understand how storytelling works as a didactic resource and how it contributes to interdisciplinary practices in Science Education. Analysis of data and results from interviews are based on Muylaert et al. study (2014), pointing out narrative as an artisanal communication way, which conveys the interviewee's experience to a certain theme. The research presented the interdisciplinary approach as a merge of subjects on teaching Science, using the stories as resources to reach comprehension. As results, we realize the importance of teaching Science on interdisciplinarity, aiming to attribute meaning to elements presented to the students. Therefore, interdisciplinary thinking transcends the school walls, bringing knowledge of the student's own life experience to the classroom.

Keywords: storytelling, science education, interdisciplinarity.

\footnotetext{
* Mestranda em Ensino de Ciências pelo Instituto Federal de Educação Ciência e Tecnologia do Rio de Janeiro - IFRJ. E-mail: dsales.sousa@gmail.com

** Doutora em Ciências Sociais. Docente do PROPEC/Instituto Federal de Educação Ciência e Tecnologia do Rio de Janeiro - IFRJ. E-mail: maylta.anjos@ifrj.edu.br

*** Doutora em Ecologia. Docente do PROPEC/Instituto Federal de Educação Ciência e Tecnologia do Rio de Janeiro - IFRJ. E-mail: giselle.rocas@ifrj.edu.br
} 


\section{Introdução}

"Quando eu não sabia ler, brincava com os livros e imaginava-os cheios de vozes, contando o mundo" (Cecília Meireles).

O ensino de ciências (EC) contextualizado promove o alargamento da compreensão do mundo e descobertas do universo científico num mundo com caráter cada vez mais tecnológico. Ao aliar o EC à contação de histórias, desvela-se um recurso didático recheado de pluralidade de saberes, de repertórios e situações que possibilitam acessar os conceitos científicos de forma diferenciada e menos afastada da realidade dos alunos, que tem nesse recurso novas possibilidades de integração que caminham a favor de uma abordagem interdisciplinar ao avançar para searas que fortifiquem os processos de aprendizagem.

A contação de histórias serviu a muitas culturas como meio de difundir e constituir verdades, olhares e lições de vida, como memória e manutenção de tradições, ou até mesmo como difusão de novos caminhos de possibilidades e encontros de vida (BEDRAN, 2010). Atualmente, a contação de histórias aprofunda dimensões do ser e do ensino direcionado à sociedade, por via de uma oralidade, permitindo a troca de experiências entre contador e ouvinte por meio das palavras e pensamentos. Assumindoa como recurso didático, contribui para a constituição e difusão das culturas e modo de ser e pensar a humanidade no que tange ao processo de ensino e aprendizagem, aumentando e ampliando a cena do ensino de ciências na escola.

A pergunta que norteia esse estudo é: como a contação de histórias contribui para o ensino de ciências? Consideramos aqui que a contação de histórias atua como recurso didático, assumindo, portanto, o pressuposto de que ela contribui para o ensino de ciências possibilitando a prática de abordagens interdisciplinares favorecendo a aprendizagem concreta. $\mathrm{O}$ objetivo desta pesquisa foi o de compreender de que maneira a contação de histórias, como recurso didático, contribui para as ações e práticas interdisciplinares no ensino de ciências.

\section{A importância da contação de histórias articulada ao ensino de ciências}

A abordagem interdisciplinar estimula a aprendizagem acerca da decodificação dos códigos fenomenológicos, naturais e sociais que podem ser desfrutados ao ouvir e imaginar as histórias. Ela contribui e incentiva a leitura e a escrita, proporcionando 
melhor noção dos fatos, maior sentido de alteridade e maior noção de valores, afetos e sentimentos.

Nesta pesquisa entendemos por interdisciplinaridade o conceito apresentado por Fazenda (2008), pensando-a para além da junção de disciplinas, o que seria uma simples integração de conceitos, mas como "atitude de ousadia", pensando também na formação interdisciplinar do professor. Fazenda (2008) apresenta dois caminhos para o entendimento da formação interdisciplinar do professor. $\mathrm{O}$ primeiro trata da ordenação científica, que conduz à construção de saberes interdisciplinares, obrigando o professor a sair da sua zona de conforto, buscando novos caminhos e revendo sua prática. $\mathrm{O}$ segundo trata da "ordenação social", busca a relação desses saberes científicos interdisciplinares com as exigências sociais, políticas e econômicas. A contação de histórias atua justamente nessa relação, nesse desdobramento dos saberes, propiciando uma reflexão sobre o saber em relação ao mundo.

$\mathrm{Na}$ contação de histórias existe uma autoexpressão que se dá na construção do conhecimento sobre o mundo (ABRAMOVICH, 2008), o qual se dá por via interdisciplinar, expandindo e concatenando melhor o saber. Ela fortalece o ensino do ponto de vista metodológico, propiciando que sentimentos e aprendizados sejam manifestados durante a escuta de uma história, sem que a mesma seja vivida concretamente mas, que ao ser experimentada como referência/experiência que serviu ao outro, traz ao que ouve a empatia do sentir e colocar-se no lugar desse outro.

É aí que o processo de reflexão se amplia e facilita a vida e o convívio em sociedade. É aí que metáforas ganham vida e a vida ganha experiência ensinada, construída, apreendida. Em razão desses fatos e de tantos outros que poderão ao longo desse trabalho ser assinalado, que avaliamos ser a contação de histórias, no e para o ensino de ciências, uma contribuição interdisciplinar que promove momentos de leitura partilhada, estimula a formação de leitores e observadores de situações, auxilia na interação, comunicação, expressão e ludicidade, bem como amplia formas e tons no aprender e no ensinar ciências.

Nossa defesa desta tão antiga e "nova" abordagem parte de vários fatores, entre eles que é na contação que temos a metonímia do aprender e viver com prazer. Nela, o ato interpretativo, tão presente, pode incluir dos textos mais simples e básicos para pensar os fenômenos naturais, como também, textos mais complexos que podem ser 
trabalhados e harmonizados com exemplos correlacionados às atividades próximas dos ouvintes, à iniciação da pesquisa, dando assim, maior sentido ao que foi contado. $\mathrm{O}$ ato de contar histórias favorece o despertar da curiosidade e imaginação e o diálogo com a cultura local, possibilitando o exercício da cidadania (BEDRAN, 2010). Além disso, a contação de histórias, enquanto ato social e coletivo, funciona como uma ponte que liga diferentes dimensões e desperta para os significados que nos tornam mais humanos (BUSATTO, 2011).

Há toda uma sistemática própria na contação que contribui com o cotidiano escolar, o planejamento do ensino e a produção científica gerada por este (ABRAMOVICH, 2008; BUSATTO, 2011; FRANCISCO, 2015). A contação instiga e influencia a realização de pesquisa pelo olhar que mais ainda quer saber, que mais ainda quer experimentar.

É através duma história que se podem descobrir outros lugares, outros tempos, outros jeitos de agir e de ser, outra ética, outra ótica.... É ficar sabendo História, Geografia, Filosofia, Política, Sociologia, sem precisar saber o nome disso tudo e muito menos achar que tem cara de aula (ABRAMOVICH, 2008, p. 17).

É nesse contexto que se traz o ensino de ciências como aporte da contação, mantendo-o como protagonista em uma abordagem interdisciplinar de popularização da Ciência.

Há, assim, uma forte tendência na difusão de novas abordagens no ensino de ciências para que se consolide as temáticas de pesquisas que digam respeito à produção científica que se alarga, a partir de concepções epistemológicas, experimentais, históricas, sociais e culturais.

A partir de experiências vivenciadas é possível afirmar que a contação de histórias, ao trabalhar conceitos do ensino de ciências de forma contextualizada, significativa, representativa, construtiva, sedutora e prazerosa, propõe olhar integralmente aos sujeitos escolares. Segundo Francisco (2015), somam-se à contação os benefícios e a possibilidade dos trabalhos em grupo, além de momentos nos quais os alunos poderão expressar-se artisticamente sobre os contextos e conteúdos voltados ao ensino de ciências. 
As contribuições que a contação de histórias como abordagem interdisciplinar oferece, rompem barreiras referentes ao ensino e a aprendizagem, dos mais simples conceitos aos mais complexos que são trabalhados na ciência, dando leveza aos temas tratados e configurando-os dentro do cenário acerca do que é vivido e observado.

Portanto, temos na contação de histórias uma outra forma de incentivar, de instigar e seduzir os alunos à criatividade, à curiosidade, à imaginação e ao despertar de saberes que nascem das correlações, das transposições, das ressignificações ao que já se conhece. Nela, há uma real possibilidade de aproximação professor e aluno, e do saber que redunda numa maior construção do conhecimento por parte desses sujeitos do ensino e aprendizagem, que podem ter nessa abordagem elementos para pensar criticamente sobre a realidade, sobre a natureza através de um processo reflexivo do que seja a ciência.

Dessa forma, há que se pensar que a contação de histórias se constitui em uma experiência muito interessante, pois leva à compreensão da história, trabalhando com a questão cognitiva e afetiva, que buscará por parte do ouvinte referências que estarão relacionadas às histórias da vida e da realidade circundante. Da realidade que se torna concreta a cada momento que a inspiração é o entendimento toma os sujeitos ouvintes à cena. A cada vez que as relações com o sentimento são formadas.

A leitura e a oralidade produzem um movimento que acompanha as narrativas, que relacionam questões próprias do ensino de ciências, são fundamentalmente interdisciplinares, sobretudo ao estimular a participação dos ouvintes, o desenlace das histórias, o encantamento pelos casos contados, o aguçamento do pensamento crítico, proporcionando maior habilidade para o exercício de uma boa leitura de um texto científico e dos desdobramentos desses na ação prática e escolar.

Abramovich (2008) destaca que narrar histórias para os alunos:

[...] é suscitar o imaginário, é ter curiosidade respondida em relação a tantas perguntas, é encontrar ideias para solucionar questões. É uma possibilidade de descobrir o mundo imenso dos conflitos, dos impasses, das soluções que todos vivemos e atravessamos - dum jeito ou de outro - através dos problemas que vão sendo defrontados, enfrentados (ou não), resolvidos (ou não) pelas personagens de cada história (cada uma a seu modo) (ABRAMOVICH, 2008, 17). 
As narrativas lidas e contadas na abordagem interdisciplinar devem ser facilitadoras do processo de criatividade, possuir textos de boa qualidade e ser relacionadas aos conteúdos específicos de ensino de ciências.

Para o desenvolvimento de um projeto interdisciplinar com o uso da leitura e pesquisa, na contação, há que se estabelecer relações horizontais entre a leitura e a história previamente escolhida, contada por meio de um diálogo próximo entre leitor, ouvinte e texto.

Ao professor cabe perceber que esse espaço é privilegiado de ensino e de criatividade, recheada da mais profunda alteridade, onde emerge pressupostos de valorização à vida por meio da leitura, por meio de um saber e de uma aprendizagem que se somam aos novos conhecimentos, que decorre também da escuta.

Porém não podemos desconsiderar a possibilidade de desinteresse por parte dos alunos. Viana (2018) destaca que alguns professores consideram as novas mídias digitais como um empecilho às práticas de estímulo à leitura e à contação. É preciso pensar o quanto nossos alunos estão motivados para ouvir histórias.

Larrosa (2004) faz uma crítica ao ponto específico da escola, onde assinala que no processo do ensino há que se ter o aprendizado intencional e formativo do processo da escuta. A contação de histórias age nesse hiato curricular, possibilitando e ampliando saberes e aprendizagens, sobretudo no ensino de ciências, no qual a escuta aguçada é fundamental e onde há demanda de novas abordagens, que possibilitem a interação do sujeito com o saber. É na relação de troca com o outro que os conhecimentos ampliam, transformam e enriquecem as experiências de vida. A leitura e o processo de escuta apuram a sensibilização e a consciência no interesse da análise.

A interpretação dos textos contados também abre um processo de discussão de como contar histórias na perspectiva científica, como fonte interdisciplinar que valoriza ideias, formas, cores, experimentos e palavras num processo de escuta que compreende, infere e se torna ação.

Alves (2009) defende que o ato de escutar narra um tempo de apreender o que por inteiro foi falado. Portanto, a escuta de uma contação de histórias se faz na oralidade, no aprendizado mútuo, no respeito ao que se conta e como se conta, na história e nos movimentos dela. Assim aguça análise, pensamento e criticidade a bem da construção de conhecimento e participações no mundo. Ela, contação de histórias, no e 
para o Ensino de Ciências é eminentemente uma contribuição interdisciplinar que oferece, dentro dessa abordagem, pensar novos caminhos de possibilidade de aprendizagem múltiplas para que a ciência se faça mais presente, real e vivida no cotidiano das escolas.

\section{O Curso de Formação Inicial e Continuada (Curso FIC) em Contação de Histórias}

O Curso FIC em Contação de Histórias surgiu no ano de 2017, por iniciativa do Instituto Federal de Educação, Ciência e Tecnologia do Rio de Janeiro (IFRJ), Campus Mesquita, como parte do projeto "Contando Histórias, interagindo com Ciência e Sociedade para a Divulgação Científica”, possuindo carga horária de 160 horas, e pertencente ao eixo tecnológico Desenvolvimento Educacional e Social. O curso teve uma oferta inicial de 40 vagas. Realizado em parceria com a Secretaria Municipal de Educação de Barra Mansa - Sala de Leitura da Escola Municipal Vila Elmira, o curso tem o objetivo de qualificar profissionais para incentivar a reflexão e a imaginação por meio da contação de histórias que envolvam temáticas relacionadas às questões científicas, tecnológicas e sociais, com uma concepção crítica da realidade.

Os docentes do curso são professores do IFRJ, ligados à área de ciências naturais e divulgação científica, além de profissionais de instituições parceiras, ligados à área cultural e de contação de histórias. A matriz do curso é composta por disciplinas que transitam pelas áreas de ciências, meio ambiente, construção de acervos e técnicas para a contação de histórias (quadro 1).

Quadro 1 - Matriz curricular do Curso FIC em Contação de Histórias

\begin{tabular}{|c|l|c|}
\hline EIXOS TEMÁTICOS & \multicolumn{1}{|c|}{ COMPONENTE CURRICULAR } & $\begin{array}{c}\text { CARGA } \\
\text { HORÁRIA }\end{array}$ \\
\hline \multirow{2}{*}{$\begin{array}{c}\text { Eixo de Conhecimento } \\
\text { Fundamental }\end{array}$} & $\begin{array}{l}\text { A oralidade e a história da ciência - } \\
\text { elementos para contação de histórias }\end{array}$ & $16 \mathrm{~h}$ \\
\cline { 2 - 3 } & $\begin{array}{l}\text { Contando história e ciência sem } \\
\text { preconceito - linguística e os fundamentos } \\
\text { metodológicos para o contador de histórias }\end{array}$ & $16 \mathrm{~h}$ \\
\hline \multirow{2}{*}{$\begin{array}{c}\text { Eixo de Educação, Identidade, } \\
\text { Cultura e Cidadania }\end{array}$} & $\begin{array}{l}\text { Inclusão de textos imagéticos, indígenas, } \\
\text { afrobrasileiros e africanos em práticas de } \\
\text { contação de histórias em contos, fábulas e } \\
\text { mitos }\end{array}$ & $16 \mathrm{~h}$ \\
\hline
\end{tabular}




\begin{tabular}{|c|c|c|}
\hline $\begin{array}{l}\text { Vivência no mundo do } \\
\text { trabalho }\end{array}$ & $\begin{array}{l}\text { Arte do Contador de Histórias e suas } \\
\text { possibilidades de atuações na sociedade }\end{array}$ & $16 \mathrm{~h}$ \\
\hline \multirow{5}{*}{ Eixo de formação profissional } & Técnicas de contação de histórias & $22 \mathrm{~h}$ \\
\hline & Diversidades textuais e escolha de acervo & $22 \mathrm{~h}$ \\
\hline & $\begin{array}{l}\text { Histórias de divulgação científica em } \\
\text { atividades interativas }\end{array}$ & $20 \mathrm{~h}$ \\
\hline & $\begin{array}{l}\text { Contando e contextualizando a história do } \\
\text { Brasil em samba e outros ritmos }\end{array}$ & $16 \mathrm{~h}$ \\
\hline & $\begin{array}{l}\text { O meio ambiente e a sustentabilidade nas } \\
\text { poesias no ato de contação de histórias }\end{array}$ & $16 \mathrm{~h}$ \\
\hline Total & & 160 \\
\hline
\end{tabular}

Fonte: as autoras.

O curso converge para a formação de um profissional capaz de refletir sobre a sua realidade, e que seja capaz de ensinar esse processo reflexivo por meio da contação de histórias. Diante das questões que vivenciamos hoje de violência, destruição de meio ambiente, uso exacerbado dos recursos naturais, poluição e crises econômicas, se faz cada vez mais necessário que os indivíduos se tornem ativos e pensantes.

A contação de histórias, como técnica milenar de comunicação social, é um instrumento importante para avaliarmos as propostas de formação do cidadão reflexivo. A intenção é que os profissionais qualificados por esse curso sejam capazes de atuar em espaços formais e não formais de educação, promovendo a divulgação científica.

\section{O percurso metodológico escolhido}

Para alcançarmos o objetivo desse estudo, que é compreender como a contação de histórias, como recurso didático, contribui para as ações e práticas interdisciplinares no ensino de ciências, optamos por trabalhar com uma pesquisa de cunho qualitativo do tipo estudo de caso. Isso porque, ao adentrarmos metodologicamente na contação de histórias, fincamos no ensino de ciências as nossas convicções de melhor contribuição. Isso por compreender que, nessa abordagem, as práticas interdisciplinares se dão de forma satisfatória, pois o professor, ao assumir papel de mediador, por meio das 
leituras, da oralidade que o acompanha, e das narrativas escolhidas, buscará, no diálogo, perspectivas mais amplas que estabelecem relações, fortalecem a reflexão e aguçam a curiosidade a respeito do que se leu.

Como participantes dessa análise, tivemos as alunas concluintes do Curso FIC em Contação de Histórias do IFRJ, campus Mesquita, realizado de maio a outubro de 2017. A turma foi composta por 17 alunas, em sua maioria, por alunas de Graduação em Pedagogia, todas mulheres, na faixa etária de 20 a 60 anos.

Às alunas concluintes foram realizadas as seguintes perguntas: "A contação de histórias no e para o Ensino de Ciências pode ser compreendida como uma contribuição interdisciplinar? De que maneira? Pode fornecer exemplos de histórias que auxiliem nesse processo?" O objetivo dessas questões foi o de avaliar a dimensão da compreensão das alunas sobre a possibilidade da contação de histórias como abordagem interdisciplinar no e para o ensino de Ciências. O questionamento foi realizado por meio de um formulário eletrônico e, nesse processo, foram obtidas respostas de seis alunas.

A análise dos resultados foi inspirada no método de análise das entrevistas narrativas apresentada por Muylaert et al. (2014), que entendem a narrativa como forma artesanal de comunicação, que transmite a experiência do entrevistado com determinada temática. Conforme Shutze (apud MUYLAERT et al., 2014), após a transcrição do material obtido é preciso separar o conteúdo racional e concreto do conteúdo que expressa juízo de valor, respectivamente nomeados de conteúdo indexado e conteúdo não indexado. Em seguida, com o conteúdo indexado, é estabelecida uma ordem para os acontecimentos, que é denominada trajetória. Depois, o conteúdo não indexado é revisitado, e então agrupam-se as trajetórias individuais. O último passo é estabelecer semelhanças entre as trajetórias individuais, chegando-se à identificação de uma trajetória coletiva.

Também Alarcão (2011) apresenta a narrativa como instrumento de pesquisa na formação de professores. A partir da sua experiência narrada, é possível compreender não só a experiência vivida pelo sujeito, mas também perceber a reflexão que o próprio sujeito faz sobre a situação vivida, o que aponta a escolha de uma metodologia que se debruça em um caso que apresenta seus resultados no sentido processual de uma análise que reúne abordagens interdisciplinares em múltiplos recursos para a díade ensino e aprendizagem. 


\section{Resultados e discussão}

Para analisar as respostas das alunas foi necessário dividir a pergunta em três momentos: no primeiro, a resposta direta se há contribuição interdisciplinar da contação de histórias para o ensino de ciências.

Todas as alunas que responderam à questão entendem a contação de histórias no e para o ensino de ciências como uma abordagem interdisciplinar. Essa compreensão vai além do uso da contação como um recurso didático, mas a entende como algo que está no mundo. Aqui podemos retomar ao conceito de interdisciplinaridade apresentado por Fazenda (2008) onde, para além da integração das disciplinas é preciso compreender a relação dos saberes científicos com o mundo. A aprendizagem e a leitura do mundo se dão por meio da contação nos diversos espaços que vivemos.

A unanimidade de respostas afirmativas (no caso, "sim", há contribuição interdisciplinar da contação de histórias para o ensino de ciências) a essa primeira parte da questão mostra não só que as alunas perceberam as possibilidades de trabalho interdisciplinar no ensino de ciências, mas demonstra também que o objetivo do curso foi alcançado, qualificando as concluintes de forma a serem profissionais que incentivem a reflexão e a imaginação estimuladas pela contação de histórias atrelada ao ensino de ciências. No segundo momento, foram analisadas as respostas das alunas sobre: como a contação de histórias no e para o ensino de ciências pode ser uma contribuição interdisciplinar.

Neste momento foi possível trabalhar a análise das narrativas inspirando-se em Muylaert et al. (2014), que consiste em

\footnotetext{
reduzir o texto gradativamente, operando-se com condensação de sentido e generalização, divide-se o conteúdo em três colunas, na primeira fica a transcrição, na segunda coluna a primeira redução e na terceira apenas as palavras-chave (p. 196).
}

Das respostas das alunas concluintes emergiram algumas palavras-chave que resultaram nas seguintes categorias: diálogo com outras áreas/disciplinas, tema gerador e seleção de repertório dentro do contexto. Essas categorias demonstraram a trajetória coletiva que demonstra um caminho para o trabalho interdisciplinar no ensino de ciências por meio da contação de histórias. 
Desta forma, a partir das respostas dadas pelas alunas concluintes, foram organizadas categorias que se complementam, buscando compreender a trajetória coletiva da reflexão dos sujeitos da pesquisa acerca da questão apresentada. A organização das categorias acabou resultando em um caminho de como trabalhar com a contação de histórias no ensino de ciências sob uma abordagem interdisciplinar. Caminho este que não deve ser entendido como um simples passo a passo, mas um caminho que emerge como resultado da experiência vivida por essas alunas no curso de Contação de Histórias.

A primeira categoria surgida da fala das alunas foi o Diálogo com outras áreas/disciplinas. Essa resposta é um tanto quanto óbvia, já que na própria questão se apresenta a possibilidade de um trabalho interdisciplinar. Porém, o texto das alunas apresentou a possibilidade de trabalho interdisciplinar não só entre a contação de história e o ensino de ciências, mas de um trabalho conjunto com outras disciplinas, como história, filosofia e artes, conforme fragmentos abaixo:

A2- "É uma contribuição interdisciplinar pois dialoga com várias áreas do saber, como por exemplo, com a literatura, arte, filosofia, entre outras"

A3- "A contação implica na articulação de ações disciplinares que buscam um interesse em comum ou não”; “... garantir a construção de um conhecimento globalizante, rompendo com os limites das disciplinas"

A5- "A contação de história pode ser usada para o ensino de ciência, onde, ao escolher o livro para a atividade, o professor ou contador consegue, além de tratar o tema central, que pode ser ou não a divulgação científica junto com a sua atividade, trabalhar matérias como português, história, arte" (grifo das autoras).

O aparecimento das disciplinas história e filosofia como possíveis para o trabalho interdisciplinar foi interessante, pelo fato de já existirem discussões sobre o uso de História e Filosofia da Ciência (HFC) no ensino de ciências. Apesar de o objetivo do curso não ter sido trabalhar especificamente com HFC, esta emerge na fala das alunas de forma intuitiva, percebendo-se a necessidade da interação da Ciência com as demais áreas que a tornam mais significativa.

Isso nos remete à fala de Abramovich (2008), onde por meio da história é possível aprender sobre história, geografia, filosofia, política ou qualquer tema, sem precisar dar nome a tudo isso. Ou seja, esta proposição dialoga com o entendimento de 
interdisciplinaridade do qual fala Fazenda (2008), extrapolando a interação entre as disciplinas e buscando uma forma de compreensão do mundo.

A segunda categoria construída a partir da fala das alunas foi a necessidade de um Tema gerador:

\begin{abstract}
A3- "A contação implica na articulação de ações disciplinares que buscam um interesse em comum ou não"

A5- "A contação de história pode ser usada para o ensino de ciência, onde, ao escolher o livro para a atividade, o professor ou contador consegue, além de tratar o tema central, que pode ser ou não a divulgação científica, junto com a sua atividade trabalhar matérias como português, história, arte." (grifo das autoras).
\end{abstract}

Observa-se que a definição do tema que será trabalhado pelas diversas disciplinas é importante, pois é este que possibilitará a integração entre elas. O Tema Gerador, desta forma, será a base para a construção do trabalho interdisciplinar, promovendo o diálogo e a comunicação entre as disciplinas.

Em seguida, apresenta-se a categoria Seleção de Repertório. Definindo-se um tema central para o trabalho interdisciplinar, é necessário escolher um repertório adequando-o para a contação de histórias, conforme fragmentos das falas das alunas:

\footnotetext{
A5- "A contação de história pode ser usada para o ensino de ciência, onde, ao escolher o livro para a atividade, o professor ou contador consegue, além de tratar o tema central, que pode ser ou não a divulgação científica, junto com a sua atividade, trabalhar matérias como português, história, arte.

A6- "Isso acontece selecionando a história e o enredo dentro do contexto a ser trabalhado pelo contador." (grifo das autoras)
}

Os exemplos e possibilidades para este repertório serão apresentados no terceiro momento da pergunta problema desta pesquisa, porém cabe salientar a relevância da escolha adequada do repertório. Para as alunas, a história escolhida pode ser ou não de divulgação científica, mas necessariamente precisa ser coerente com o Tema Gerador, precisa estar dentro do contexto que se quer apresentar e desta forma dará significado à aprendizagem que é a próxima categoria apresentada.

A aprendizagem significativa aparece como o resultado dessa reflexão, realizada pelas alunas, sobre como se dá o trabalho interdisciplinar da contação de histórias, no 
ensino de ciências. A contação de histórias desta forma “... funciona como uma forma intencional e lúdica de divulgar a ciência, a qual proporciona a aprendizagem significativa dos conteúdos" (A6, grifo das autoras).

A contação de histórias possibilita também dar significado/sentido ao que é ensinado para os alunos, de forma que o que se aprende seja compreendido como algo que faz parte da sua vida, do seu cotidiano. É a contação de histórias uma forma de compreensão do mundo pelo indivíduo e de seu lugar nesse mundo (BEDRAN, 2010; BUSATTO, 2011). Entende-se a necessidade de desfragmentar o conhecimento que estava depositado nas diversas gavetas, romper com o conceito de educação bancária (FREIRE, 1987) e pensar na formação como um todo, na formação do indivíduo de forma integral.

\begin{abstract}
A3 - "Fazer ligação, unir, conectar, dar sentido, complementar dando significado àquilo que é aprendido e ensinado. Sendo observado que a interdisciplinaridade é um trabalho pautado no diálogo entre seres humanos e as disciplinas, possibilitando conexões com a leitura que proporciona a todo momento o envolvimento e desenvolvimento com o ensino e aprendizagem". [...] A interdisciplinaridade oferece uma nova postura diante do conhecimento, uma mudança de atitude em busca do contexto do conhecimento, em busca do ser como pessoa integral".
\end{abstract}

Desta forma é possível compreender, a partir das falas das alunas, que a contação de histórias possibilita o trabalho interdisciplinar no ensino de ciências, tornando a aprendizagem dos conteúdos científicos mais significativa e próxima do entendimento dos alunos, tornando a aprendizagem no ensino de ciências mais lúdica, trabalhando a criatividade e também o entendimento da Ciência não como algo fragmentado e distante, mas como algo que está presente em nosso cotidiano e capaz de se entrelaçar com as demais áreas do conhecimento.

O terceiro momento de análise é observar as respostas das alunas diante do seguinte questionamento: "Pode trazer exemplos de histórias que auxiliem nesse processo?"

Diante deste questionamento, surgiram diversas formas de contação de histórias que não só as oriundas dos livros infantis. Observou-se também que, sob a ótica das alunas, não há necessidade de utilizar-se somente de histórias que tenham cunho 
científico. É possível utilizar-se de textos que não tenham somente a pretensão de fazer divulgação científica.

As propostas de repertório apresentados pelas alunas foram divididas em três categorias: Livros, desenhos animados e outras formas narrativas, conforme apresentados no quadro 2 .

Quadro 2 - Histórias que articulam contação e ensino de ciências.

\begin{tabular}{|l|l|}
\hline \multicolumn{1}{|c|}{ Categorias } & \multicolumn{1}{c|}{ Exemplos } \\
\hline Desenhos animados & A1- "Show da Luna" \\
& A6- "Peixonauta; Show da Luna; Castelo Rá-tim-bum" \\
\hline Outras formas narrativas & A2- "Contação com recursos visuais" \\
& A3- "Aulas com Julinho. O que tem na minha boca. A \\
& floresta e seus encantos." \\
\hline Livros & A6- "Zum, Zum, Zum: a doce história das abelhas" \\
& A3- "Monteiro Lobato" \\
\hline
\end{tabular}

Fonte: as autoras.

É interessante observar o aparecimento não só de narrativas ou livros, mas também de desenhos animados, no repertório exemplificado pelas alunas. Uma das justificativas das alunas para o uso de desenhos animados para a contação de histórias é o fato de a tecnologia transformar o modo de se contar histórias com conteúdos científicos de maneira lúdica:

\footnotetext{
A1- "Como exemplo, posso citar um desenho de censura livre, mas especialmente amado por crianças de 2 a 6 anos, "O Show da Luna", o episódio sobre "como a água vira chuva". A-PAI-XO-NAN-TE! Com a linguagem adequada e visuais muito bem explorados, ensina o processo das chuvas, inclusive tranquilizando as crianças quanto aos relâmpagos e trovoadas. [...] Por que um desenho animado como exemplo? Oras, viva a tecnologia! Os desenhos sempre nos contaram histórias, e participaram da nossa formação sem que percebêssemos".
}

Esta fala é importante também para refletir sobre o papel do professor como mediador do conhecimento. A tecnologia não vem para substituir o professor em sala de aula, mas como algo que faz parte da vida dos alunos, e o professor não pode ficar alheio a isso. Nesse sentindo, o pensar interdisciplinar transcende as paredes da escola, trazendo conteúdos de vivência do próprio aluno para a sala de aula. 


\section{Considerações finais}

O tema escolhido ofereceu a oportunidade de pesquisar a contação de histórias, traçando um paralelo no que se faz no ensino de ciências. Acreditamos ser essa apenas mais uma contribuição que caminha no campo interdisciplinar, fortalecendo a compreensão e atiçando o imaginário que se tem dos fenômenos naturais.

A liberdade das palavras na contação é fundamental, porque provoca interlocução com o discurso escrito organizado, e pode-se chegar à conclusão de que ela pode sim contribuir para o ensino de ciências, apresentando-se como importante elemento para o trabalho interdisciplinar no ensino da disciplina.

A partir das falas das alunas concluintes do Curso FIC em Contação de Histórias, observou-se a importância de se trabalhar com o ensino de ciências atrelado às demais disciplinas, de forma a dar significado aos elementos que são apresentados aos alunos. A ludicidade tão presente na contação de histórias também se apresentou como um elemento importante no ensino de ciências.

Outro fator importante é a escolha do repertório, que deve ser contextualizado e adequado ao ensino e não necessariamente de conteúdos de divulgação científica. $O$ repertório pode ser composto não só dos conteúdos dos livros ou narrativas, mas também de desenhos animados.

Estes desenhos aparecem como uma nova forma de se contar uma história, mostrando que a tecnologia pode estar presente em sala de aula, não para ocupar o papel do professor, mas para transformar a sua forma ensino.

Por fim, percebemos que a contação de histórias contribui não só para o ensino de ciências, mas para todas as formas de ensino. A contação enquanto forma de arte pode ser o elemento que faz a ligação entre as diversas disciplinas, promovendo mais significado, reflexão e sensibilização dos alunos para a compreensão não só dos conteúdos ensinados na escola, mas também para compreensão do mundo e de sua realidade.

\section{Referências}

ABRAMOVICH, F. Literatura infantil: gostosuras e bobices. 5. ed. São Paulo: Scipione, 2008.

ALARCÃO, I. Professores reflexivos em uma escola reflexiva. 8. ed. São Paulo: Cortez, 2011. 
ALVES, R. Escutatória. Instituto Rubem Alves. Disponível em: https://institutorubemalves.org.br/rubem-alves/carpe-diem/cronicas/escutatoria-3/. Acesso em: 20 de fevereiro de 2018.

BEDRAN, B. M. Ancestralidade e contemporaneidade das narrativas orais: a arte de cantar e contar histórias. 2010. Dissertação (Mestrado em Ciência da Arte) Universidade Federal Fluminense. Niterói, RJ, 2010. Disponível em: http://www.artes.uff.br/dissertacoes/2010_bia_bedran.pdf. Acesso em 26 jul. 2018

BUSATTO, C. A arte de contar histórias no século XXI: tradição e ciberespaço. 3. ed. Petrópolis: Vozes, 2011.

FAZENDA, I. Interdisciplinaridade-transdisciplinaridade: visões culturais e epistemológicas. In: (Org.). O que é interdisciplinaridade? São Paulo: Cortez, 2008. p. 17-28.

FRANCISCO, Fernanda Ruiz. A contação de histórias no ensino de ciências: um recurso didático. 2015. Trabalho de conclusão de curso (Pedagogia) - Universidade Estadual Paulista, São Paulo, SP, 2015. Disponível em: https://repositorio.unesp.br/handle/11449/126696. Acesso em 26 jul. 2018.

FREIRE, P. Pedagogia do Oprimido. 17 ed. Rio de Janeiro: Paz e Terra. 1987.

LARROSA, J. Linguagem e educação depois de Babel. Belo Horizonte: Autêntica, 2004.

MUYLAERT, C. J. et al. Entrevistas narrativas: um importante recurso em pesquisa qualitativa. Revista da Escola de Enfermagem da USP, São Paulo, p. 193-199, 2014. Disponível em: http://www.scielo.br/pdf/reeusp/v48nspe2/pt_0080-6234-reeusp-48nspe2-00184.pdf. Acesso em: 26 jul. 2018.

VIANA, C. Histórias para contar ciências: possibilidades lúdicas para a alfabetização científica. 2018. Dissertação (Mestrado em Educação em Ciências e Matemática) Universidade Federal Rural do Rio de Janeiro. Seropédica, RJ, 2018. Disponível em: http://cursos.ufrrj.br/posgraduacao/ppgeducimat/files/2018/06/Cassia-Viana.pdf Acesso em: 26 jul. 